\title{
Algumas considerações sobre o estatuto da crítica em Nancy Fraser ${ }^{1}$
}

Nathalie Bressiani de Almeida

\section{Resumo:}

Em Redistribution or Recognition?, Nancy Fraser reformula a sua teoria a partir de uma reflexão acerca do que é Teoria Crítica. Ao se dar conta dos diversos problemas presentes em uma primeira formulação dada a ela a seu projeto crítico, Fraser repensa o vínculo entre a crítica e o diagnóstico de época e tenta rearticular os dois momentos de sua teoria, o descritivo e o normativo, por meio do que ela chama de uma relação dialética entre imanência e transcendência. Tendo isso em vista, esse artigo procurará, explorando os desenvolvimentos e mudanças do estatuto da crítica no interior do modelo teórico proposto por Fraser, explicitar o que ela entende por Teoria Crítica; isso, com o objetivo de problematizar o critério normativo utilizado por ela na avaliação do presente e a relação que se estabelece entre ele e as configurações sociais atuais.

Palavras-chave: Teoria Grítica, normatividade, crítica situada e teoria da justiça

I Este artigo foi escrito no final do ano de 2007. 
O modelo teórico apresentado por Nancy Fraser, que se caracteriza, desde suas primeiras formulações, por uma postura crítica perante o presente, defende uma concepção dualista de injustiça de acordo com a qual as configurações sociais atuais estariam perpassadas por duas formas analiticamente distintas e irredutíveis de injustiça. Existiriam, de acordo com ela, injustiças relacionadas a desigualdades materiais que, consequências do funcionamento do sistema econômico, estariam relativamente descoladas de um segundo tipo de injustiças que, ao contrário dessas, estariam intrinsecamente ligadas à esfera da cultura. Assim, o diagnóstico de época proposto por Fraser, o qual parece retomar em alguma medida o dualismo habermasiano entre sistema e mundo da vida, faz uma distinção entre dois tipos de injustiças: aquelas relacionadas à distribuição de bens materiais, que estariam ancoradas na economia-política e, portanto, em formas sistêmicas de integração, e as relacionadas ao reconhecimento, dependentes de padrões de valoração cultural e, consequentemente, de formas sociais de integração.

Temos, contudo, que, se o pensamento de Fraser é, como um todo, marcado por uma postura crítica frente às configurações sociais existentes, nas quais a autora identifica duas formas distintas de injustiças, o estatuto do fundamento proposto por ela a essa mesma postura, assim como a relação que se estabelece entre ela, a saber, a crítica, e o próprio presente, sofre diversas modificações no desenrolar de seu desenvolvimento teórico.

Em Unruly Practices. Power, discourse and gender in contemporary social theory, coletânea de artigos publicada em I989, Fraser começa a desenvolver - ainda fortemente influenciada tanto por autores do pragmatismo norte-americano, como Richard Rorty, como por Foucault e por diferentes autores e vertentes do pós-modernismo e do desconstrucionismo francês, tal como Derrida - um modelo crítico, no qual a crítica, como ela mesma afirma, prescinde de qualquer fundamentação de caráter filosófico. Sem procurar estabelecer um distanciamento com o presente ou mesmo uma dimensão normativa que, relativamente afastada das relações sociais, possibilitasse a avaliação destas por uma concepção determinada de justiça, o modelo teórico proposto por Fraser defende uma compreensão de teoria crítica pautada pela definição de Marx, segundo a qual Teoria Crítica é "o autoaclaramento das lutas e desejos de uma época". ${ }^{2}$ Definição essa que, como afirma a autora, não reivindica qualquer

2 Fraser, N. "What's Critical about Critical Theory? The Case of Habermas and Gender". In: Unruly Practices. Power, discourse and gender in contemporary social theory. Minneapolis: University of Minnesota Press, I989. p. II3. ["Que é Crítico na Teoria Crítica? O Argumento de Habermas e o Gênero”. In: Feminismo como Crítica da Modernidade, Benhabib, Seyla e Cornell, Drucilla (orgs.), Rio de Janeiro: Rosa dos Tempos, I987, p. 38.] 
status epistemológico e chega a insinuar que "com respeito à justificação não há absolutamente diferença interessante, do ponto de vista filosófico, entre uma teoria crítica da sociedade e uma teoria acrítica", ${ }^{3}$ mas, ao contrário, uma importante diferença política. A concepção de Teoria Crítica da qual Fraser lança mão na elaboração de seu modelo teórico defende, dessa forma, que o programa de pesquisa e a estrutura conceitual de uma teoria social crítica devem ser projetados "com um olho nos objetivos e atividades daqueles movimentos sociais opositores com os quais tem uma identificação partidária embora não acrítica". ${ }^{4}$

Em uma primeira formulação de sua teoria, portanto, o momento propriamente crítico do pensamento de Fraser não é, em termos gerais, separado do diagnóstico do tempo elaborado por ela; a crítica é pensada e estruturada conceitualmente com vistas aos movimentos contestatórios existentes e está, dessa forma, intrinsecamente atrelada a eles. $O$ estatuto da crítica nesses primeiros escritos de Fraser não possui, assim, qualquer relação com uma concepção determinada de justiça; pautado pelas reivindicações de caráter oposicionista dos movimentos sociais, sua teoria social não lança mão da filosofia e de questões de fundamento. Deve-se, contudo, ressaltar que, mesmo que a estrutura conceitual de sua teoria seja elaborada a partir das reivindicações dos movimentos sociais, Fraser não pretende adotar uma posição acrítica frente a esses movimentos contestatórios. O mínimo de distanciamento perante as reivindicações dos movimentos sociais, necessário para que a autora mantenha, com relação a elas, uma postura crítica é proporcionado pelo caráter agregador da teoria por ela desenvolvida. Sem uma concepção de justiça que lhe permita avaliar de fora os movimentos e conflitos sociais contestatórios, Fraser procura criticá-los por meio da conciliação de seus diversos objetivos.

É nesse sentido que, no primeiro artigo de Justice Interruptus, Fraser parte dos objetivos dos movimentos sociais, isto é, redistribuição material e reconhecimento cultural, para concluir, depois de contrapô-los, que o único meio de conciliá-los proveitosamente é lançando mão de medidas de caráter transformativo (reestruturação do sistema econômico, no caso da redistribuição e desconstrução de identidades fixas, no caso do reconhecimento) e não de medidas de caráter afirmativo (redistribuição de renda por meio de programas assistencialistas, no caso da redistribuição, e afirmação de identidades de grupos sociais marginalizados, no do reconhecimento). É desta forma que, por meio de uma tentativa de agregar as diferentes reivindicações dos movimentos sociais, Fraser

3 Idem, Ibidem.

4 Idem. Ibidem. (grifo meu) 
Algumas considerações sobre o estatuto da crítica em Nancy Fraser

procura adotar, frente a eles, uma postura crítica, sem recorrer, para isso, a uma concepção específica de justiça. ${ }^{5}$

Temos, entretanto, que mesmo sem pretender lançar mão de qualquer concepção universalista de justiça ou de fundamentações filosóficas, a teoria proposta por Fraser não deixa de ter, como aponta Seyla Benhabib, uma concepção implícita de justiça. Segundo Benhabib, a atual existência de uma pluralidade de concepções de boa vida e de objetivos dos movimentos sociais não nos permitiria encontrar "um conjunto único de critérios constitutivos sobre o qual haveria um tamanho consenso universal a ponto de podermos simplesmente assumir que pela sua justaposição às praticas atuais em andamento, cumprimos o objetivo de uma crítica social imanente". ${ }^{6}$ Sem tomar a totalidade das reivindicações feitas pelos movimentos sociais como ponto de partida, as quais não são sempre de esquerda ou mesmo condizentes com a declaração dos direitos humanos, Fraser parece possuir, desde o início, um comprometimento com os movimentos oposicionistas de esquerda que não violam os direitos humanos, recusando, assim, tanto os movimentos conservadores, como as reivindicações de grupos fascistas, o que, sem a pressuposição de um conceito de justiça, não seria possível. Embora a estrutura crítica do modelo teórico proposto por Fraser tenha, aparentemente, como fundamento as reivindicações feitas pelos movimentos sociais, ela não é pensada a partir de todas essas reivindicações, as quais são previamente filtradas por uma concepção de justiça que não é esclarecida ou explicitada no decorrer do livro. Dessa forma, o pensamento de Fraser que, como vimos, procura elaborar sua estrutura crítica a partir dos movimentos sociais e possuiria, como objetivo, o aclaramento de suas reivindicações, consiste, de fato, de dois diferentes momentos: o crítico, o qual, como aponta Benhabib, não deriva diretamente das lutas sociais, e o descritivo, no qual a autora apresenta, em termos gerais, seu diagnóstico do presente. ${ }^{7}$

5 Cf. Fraser, N. "From Redistribution to Recognition? Dilemmas of Justice in a 'Postsocialist' Age". In: Justice Interruptus, Critical reflections on the 'postsocialist' condition. New York \& London: Routledge, I997, pp. II-40. Cf. também: Fraser, N. "What's Critical about Gritical Theory?”; Fraser, N. "Social Criticism without Philosophy: An Enconter between Feminism and Postmodernism”, in Theory Culture and Society, I988, v. 5; Silva, F. Gonçalves. "Iris Young, Nancy Fraser e Seyla Benhabib: uma disputa entre modelos críticos". In: Teoria Crítica. no prelo.

6 Benhabib, S. Situating the Self. Gender, Community and Postmodernism in Contemporary Ethics, New York: Routledge, I992, p. 226. Cf. também: Benhabib, S. "Sobre um modelo deliberativo de racionalidade democrática". In: Democracia Deliberativa. Werle, D. e Melo, R. S.(orgs.), São Paulo, Esfera Pública, 2007. Assim como: Silva, F. Gonçalves. Op., cit., parte III.

7 Vale a pena ressaltar que em Unruly Practices Fraser ainda não trabalha diretamente com o dualismo entre redistribuição e reconhecimento já presente em Justice Interruptus. Da mesma maneira, parece-nos 
Esses dois momentos, contudo, não aparecem no texto separadamente, ao contrário, o diagnóstico do tempo apresentado pela autora já contém uma distinção entre relações sociais justas e injustas, assim como entre injustiças econômicas e culturais e, portanto, não é meramente descritivo. É, entretanto, preciso ressaltar que, embora a descrição da sociedade tenha uma dimensão crítica, esta não possui uma relação intrínseca com aquela. A critica não é diretamente extraída dos movimentos sociais; se Fraser encontra na sociedade duas formas de injustiça que condizem com dois tipos de reivindicações é porque ambas foram pensadas a partir de uma concepção implícita de justiça. Se não fossem as demandas dos movimentos sociais o fundamento da crítica, não seria possível Fraser identificar apenas duas formas de injustiças ou mesmo um consenso sobre a existência e a veracidade delas. Como indica Benhabib, as configurações e práticas sociais são classificadas como justas e injustas por um critério pressuposto de justiça que lhes é alheio; a perspectiva crítica não é extraída do presente, estando, de fato, descolada dele. A crítica situada que Fraser procura elaborar estaria, assim, ao contrário dos objetivos da própria autora, afastado das práticas sociais das quais ela procura partir. As relações sociais e as reivindicações feitas pelos movimentos sociais, quando apresentadas, já passaram por uma avaliação: elas já são tidas como justas ou injustas e, portanto, já foram consideradas sob o ponto de vista da justiça, ou melhor, do que Fraser entende por justiça. O que Fraser compreende por justiça, contudo, não é explicitado e dá margem ao surgimento de algumas dificuldades.

O conceito de justiça proposto por Fraser não é problematizado nem constitui o objeto privilegiado de estudo de nenhum dos artigos do livro. O que a autora entende por justiça e, portanto, o que ela caracteriza como injusto, não é desenvolvido, embora perpasse o diagnóstico do presente exposto por ela e, principalmente, a crítica direcionada, por ela, à sociedade; sendo na introdução e no início do primeiro de seus artigos, onde se encontram os dois momentos nos quais ela indica, de maneira mais incisiva, o que poderíamos entender por justiça no interior de sua teoria.

possível identificar algumas outras pequenas mudanças no pensamento de Fraser entre a publicação desses dois livros, uma delas, que nos interessa mais diretamente, diz respeito ao fato de que, mesmo sem defender qualquer concepção universalista ou específica de justiça, em Justice Interruptus, Fraser não mais faz menção à definição de Teoria Crítica atribuída, por ela, a Marx. Mudança essa que poderíamos ver como uma indicação do desenvolvimento que Fraser iria dar a sua teoria, mas que não nos parece muito significativa uma vez que, ainda aqui, Fraser não defende a necessidade de um critério normativo para que as relações sociais pudessem ser avaliadas. Cf. Fraser, N. Unruly Practices; assim como, Justice Interruptus. 
O vínculo entre justiça e igualdade social é estabelecido já na introdução, onde ela diz que "nenhum projeto sucessor ao socialismo, que seja defensável, pode simplesmente rejeitar o comprometimento com a igualdade social em favor das diferenças culturais". ${ }^{8}$ Tal como é ali afirmado, Fraser defende que aqueles movimentos que, ao lançarem mão de políticas de identidade, rejeitaram a universalidade de quaisquer "sonhos comuns" e, portanto, a existência de regras que possuam validade universal, são destituídos de qualquer relação com a justiça. A afirmação das diferentes identidades, como um fim em si mesmo e não como um meio para a obtenção de igualdade social, nada tem a ver com justiça. Segundo Fraser, seria somente na medida em que combatem a pretensa universalidade de regras e condutas que são, de fato, particulares, que as políticas de identidade possuiriam um comprometimento com a igualdade social e, consequentemente, com a justiça. Temos, assim, que o modelo teórico desenvolvido por Fraser, nessa primeira formulação, parece entender a justiça como equivalente a igualdade social.

A reflexão sobre justiça se restringe, no entanto, a algumas passagens que a relacionam com a obtenção de igualdade social, igualdade essa que, em outros trechos, parece ser equivalente à igualdade material, como no início de "Da redistribuição ao reconhecimento?”, onde ela faz a seguinte afirmação:

(...) justiça hoje requer tanto redistribuição quanto reconhecimento. E eu me proponho a examinar a relação entre eles. Em parte, isso significa descobrir como conceitualizar reconhecimento cultural e igualdade social de forma que ambos se sustentem mutuamente e não prejudiquem um ao outro. ${ }^{9}$

Nesse momento, Fraser parece fazer uma distinção entre as questões de reconhecimento e as de igualdade social que, por sua vez, diriam respeito apenas àquelas referentes à redistribuição igualitária de bens e riquezas. Temos, contudo, que, se para Fraser, uma sociedade justa seria aquela em que há igualdade social - uma vez que a justiça é entendida nesses termos - e igualdade social equivale à igualdade material, nada tendo a ver com reconhecimento cultural, a concepção de justiça por ela defendida, estaria deixando de fora as questões relativas ao reconhecimento e contrariando os objetivos de seu projeto crítico que, segundo ela, procura abordar tanto as injustiças relativas ao reconhecimento quanto as relativas à redistribuição. ${ }^{10}$

8 Ibid., p. 4 .

9 Ibid., p. I2.

IO Para respeitarmos o espírito e os objetivos do trabalho de Fraser, buscamos considerar que, para melhor destacar o dilema que estabelece entre igualdade e diferença, quando trata das medidas 
Outra dificuldade, no que se refere ao conceito de justiça pressuposto pela autora, surge quando ela afirma que reivindicações que desrespeitam os direitos humanos são inaceitáveis, mesmo quando promovem igualdade social. Isso porque justiça, enquanto igualdade social, estaria subordinada a um segundo critério, os direitos humanos, cujos fundamentos não são, em momento algum, abordados.

Dessa forma, com o objetivo de apresentar uma teoria social sem filosofia, Fraser propõe uma distinção entre duas formas de injustiças que estariam ancoradas, cada uma, em um diferente objetivo interno às reivindicações dos movimentos sociais; vimos, contudo, que, como aponta Benhabib, a pluralidade de demandas e de reivindicações, as quais entrariam, muitas vezes, em conflito entre si, não são passíveis, sem que se lance mão de um critério de justiça, de tal redução. Uma vez que a sociedade contemporânea possui, como um todo, uma enorme multiplicidade de lutas sociais e de reivindicações, dentre as quais várias não condizem com a definição dual de injustiça proposta por Fraser, a formulação de um modelo crítico totalmente situado não se mostra possível sem que se adote, previamente, um critério normativo que, externo, permita a avaliação destas mesmas lutas e reivindicações. Critério este que, segundo Benhabib, não deixa de prescindir da filosofia. ${ }^{\text {II }}$

Vemos, assim, que, na tentativa de desenvolver um modelo teórico situado no qual a crítica social não lançaria mão de questões filosóficas ou de fundamentos últimos, Nancy Fraser não pretende possuir qualquer critério normativo que não seja ele mesmo um reflexo crítico dos objetivos presentes nas lutas e conflitos sociais. Temos, contudo, que, mesmo que o pensamento de Fraser não possua, até a publicação de Justice Interruptus, uma preocupação explicita com a problematização do conteúdo normativo dos critérios de justiça, ele pressupõe uma concepção de justiça que, sintomaticamente, não é claramente elaborada. Justiça é, em vários momentos, identificada com igualdade social, mas não se mostra possível, partindo dessa identificação, propor uma sistematização dos critérios de justiça por ela estabelecidos.

afirmativas e transformativas no âmbito do reconhecimento e da redistribuição, ela, em um primeiro momento do texto, entende reconhecimento cultural como afirmação das identidades e, portanto, das diferenças. Desta forma, antes da distinção entre medidas afirmativas e transformativas, reconhecimento equivale a políticas de identidade e é, por isso, diferente de igualdade social. Afirmação das diferenças é uma estratégia que caminha na contracorrente da igualdade social e é, por esse motivo, descartada pela autora. Longe de ignorar as questões de reconhecimento, contudo, o que Fraser faz é tentar compatibilizá-las com aquele que parece ser seu critério de justiça, isto é, "(...) acessar as reivindicações de reconhecimento do ponto de vista da igualdade social”. Idem.

II Gf. Benhabib, S. Situating the Self. p. 226. 
Algumas considerações sobre o estatuto da crítica em Nancy Fraser

É, parece-nos, na tentativa de superar esses problemas, que Fraser reformula sua teoria e, incorpora a ela um critério de justiça que, externo, possibilitaria a avaliação das reivindicações dos movimentos sociais, assim como a diferenciação entre injustiças econômicas e culturais. ${ }^{12}$ Em seus escritos mais recentes há, portanto, uma preocupação em explicitar o critério normativo por meio do qual as relações sociais são classificadas como justas ou injustas, assim como em mostrar quais são seus fundamentos e sua relação com o diagnóstico do tempo. Muda, desta forma, não somente a concepção de Teoria Crítica defendida pela autora, como o papel atribuído por ela à filosofia que, antes, deveria ser deixada de lado. Em uma recente reformulação de sua teoria, Fraser passa, então, a adotar como base de seu modelo teórico um princípio universal de justiça que possibilite a avaliação das reivindicações dos diferentes movimentos sociais e o estabelecimento de quais, dentre eles, são legítimos. A partir de então, a estrutura crítica da teoria por ela elaborada deixa de ser pensada a partir dos movimentos sociais, tornando-se externa e não mais interna às reivindicações feitas pelos diversos segmentos e grupos da sociedade.

Temos, dessa forma, que, ao se dar conta dos diversos problemas presentes em seu projeto crítico, Fraser repensa o vínculo entre a crítica e o diagnóstico de época e tenta rearticular os dois momentos de sua teoria, o descritivo e o normativo, por meio do que ela chama de uma relação dialética entre imanência e transcendência. Apresentando, então, uma diferente concepção do que seria Teoria Grítica, Fraser procura mostrar que o critério normativo que permite a avaliação do presente não estaria totalmente afastado da facticidade nem, ao contrário, contido nas reivindicações dos movimentos sociais. Assim, se por um lado, a autora passa a incorporar em seu modelo crítico uma teoria da justiça que, tal como ela afirma, é pensada a partir da filosofia moral e não esta dada imediatamente nos movimentos sociais, por outro, ela defende que essa teoria, responsável pela crítica, não pode estar descolada das práticas e configurações sociais atuais. Como afirma Fraser:

A crítica adquire tração somente na medida em que ela revela tensões e possibilidades que são, em algum sentido, imanentes à configuração atual. (...) Não satisfeitos em meramente explicar os significados sedimentados nas tradições existentes, ambos [Fraser e Honneth] assumimos que a crítica só possui um potencial radical se uma lacuna entre a norma e o dado é mantida aberta. E nós dois assumimos que normas

I2 Em "Reframing Global Justice", Fraser apresenta uma terceira dimensão de justiça, a dimensão política que, segundo ela, teria se tornado saliente com o processo de globalização. Cf. Fraser, N. "Reframing Global Justice". New Left Review, n. 36, 2005, pp. 69-90. 
válidas transcendem o contexto imediato que as gerou. (...) ambos procuramos um ancoramento no mundo social que aponte, simultaneamente, para além dele. ${ }^{\mathrm{I} 3}$

Na tentativa de conectar a crítica ao seu contexto social sem com isso refleti-lo acriticamente, Fraser passa a ver os movimentos sociais que, segundo ela, possuem a vantagem "de estarem sujeitos ao escrutínio crítico em debate aberto", como um dos pontos de referência empíricos de sua teoria. Sua intenção não é, entretanto, a de vê-los como os portadores da emancipação ${ }^{\mathrm{I} 4} \mathrm{e}$, nem mesmo, a de atribuir a eles o caráter de fundamento de seu modelo teórico. Para Fraser, não se deve estabelecer um ponto de referência privilegiado, ao contrário, o melhor é "estabelecer múltiplos pontos de entrada na realidade social, sem atribuir privilégio absoluto a nenhum deles, submetendo cada um deles a uma potencial revisão sob a luz dos outros". ${ }^{15}$ Os movimentos sociais são, dessa forma, um dos pontos de referência empíricos propostos por Fraser em sua teoria; não é deles, no entanto, que a autora extrai o conteúdo normativo da crítica.

Os movimentos sociais são uma das pedras de toque que guiam empiricamente o trabalho de Fraser, o que, contudo, não tem como consequência que o critério de justiça que será por ela elaborado seja pautado pelas reivindicações desses mesmos movimentos. Tal como é por ela afirmado, na contramão de sua posição

I3 Fraser, N. "Distorted Beyond All Recognition: A Rejoinder to Axel Honneth". In Redistribution or Recognition? A Political-Philosophical Exchange. ed. cit., p. 202. Em "The Point of Recognition: A Rejoinder to the Rejoinder", Honneth afirma que a compreensão que ele tem de Teoria Crítica implica uma relação mais forte entre imanência e transcendência do que Fraser parece supor. Cf. Honneth, A. "Der Pointe der Anerkennung. Eine Entgegnung auf dir Entgegnung”. In: Umverteilung oder Anerkennung? Eine PolitischePhilosophische Kontroverse. Frankfurt am Main: Suhrkamp Verlag, 2003, pp. 27I-305.

I4 Honneth afirma que Fraser, ao tomar como premissa que uma teoria social deve ser normativamente orientada em direção aos movimentos sociais, está cometendo o mesmo erro de Marx, quando este definiu o proletariado como único indicador do descontentamento social. Segundo ele devem-se evitar definições dogmáticas acerca dos indicadores de tal descontentamento. Cf. Honneth, A. "Umverteilung als Anerkennung. Eine Erwiederung auf Nancy Fraserr” In: Umverteilung oder Anerkennung? , pp. I29-225. É, em resposta a essa acusação, que Fraser afirma a necessidade de múltiplos pontos de entrada na realidade social, e nega que os movimentos sociais representem, em sua teoria, um ponto de referência empírico privilegiado. Segundo ela: "Em um tempo, no qual metanarrativas marxistas perderam toda sua credibilidade, não pode haver nenhum agente da emancipação metafisicamente designado e nenhum objeto de crítica aprioristicamente identificado”. Com essa afirmação, Fraser se afasta, ainda mais, daquela primeira formulação do que seria Teoria Crítica defendida por ela em Unruly Practices. Fraser, N. “Distorted Beyond All Recognition”. In Redistribution or Recognition?. p. 200.

I5 Ibid., p. 205. 
em Unruly Practices e em Justice Interruptus, qualquer critério de justiça que tenha sido formulado partindo diretamente das reivindicações dos movimentos sociais é, na medida em que simplesmente as reflete, incapaz de avaliá-las e, portanto, acrítico. A relação que Fraser estabelece, em Redistribution or Recognition?, entre imanência e transcendência parte do que ela chama de discursos descentralizados de crítica social. Aquilo que a permite conectar a crítica ao contexto social são os paradigmas populares de justiça social, a saber, aqueles paradigmas que "constituem as gramáticas hegemônicas de contestação e deliberação da sociedade", ${ }^{16}$ paradigmas estes que, no contexto desse livro, ${ }^{17}$ são redistribuição e reconhecimento.

Os paradigmas populares de justiça social estão diretamente relacionados com as reivindicações, eles correspondem, em termos gerais, às gramáticas de contestação às quais os movimentos sociais lançam mão para fazerem suas reivindicações. Temos, portanto, que os paradigmas de justiça social não constituem o fundamento do qual Fraser deriva a estrutura normativa de seu modelo de Teoria Crítica; se esse fosse o caso, não seria possível avaliar, por exemplo, quais, dentre as diferentes lutas por reconhecimento, são ou não justas. Para Fraser, os diferentes paradigmas de justiça, assim como as reivindicações dos movimentos sociais, não constituem o fundamento da crítica, ao contrário, eles estão a ela submetidos. Nessa segunda formulação dada pela autora a sua teoria, ela defende que a adequação de tais paradigmas deve ser avaliada, pelos teóricos críticos, de duas diferentes perspectivas: a da teoria social e a da filosofia moral. Sob a perspectiva da teoria social, os teóricos críticos precisam determinar se as gramáticas de contestação são adequadas a sua estrutura social e, sob a perspectiva da filosofia moral, se as normas às quais elas apelam são moralmente válidas.

Temos, desta maneira, que a estrutura crítica do modelo teórico apresentado por Fraser não está dada no interior dos paradigmas de justiça e, embora eles constituam um ponto de referência empírico, cujo desenvolvimento aponta para além das configurações sociais existentes, não é a partir deles que Fraser elabora a dimensão crítica de sua teoria. O critério que permite estabelecer a

I6 Ibid., p. 207.

I7 Em escritos posteriores Fraser acrescenta aos dois paradigmas populares de justiça, redistribuição e reconhecimento, um terceiro, a representação. Cada um destes três paradigmas equivale a um diferente tipo de injustiça que, embora estejam intrinsecamente interligados, possuem certa autonomia frente aos outros. Redistribuição diz respeito a injustiças econômicas, reconhecimento a injustiças culturais e representação a injustiças políticas. Gf. Fraser, N. "Reframing Global Justice". ed. cit. e "Mapping the Feminist Imagination: From Redistribution to Recognition to Representation”. Constellations, v. I2, n. 3, 2005, p. 295-307. Já em Redistribution or Recognition?, Fraser aponta para a existência desse terceiro paradigma, mas não chega a desenvolvê-lo. Gf. Fraser, N. "Social Justice in the Age of Identity Politics: Redistribution, Recognition, and Participation”. In Redistribution or Recognition?. p. 67-69. 
validade moral, tanto dos paradigmas quanto das reivindicações dos movimentos sociais, é dado pela filosofia moral. Tendo, então, em vista a crítica feita por Benhabib, Fraser defende, na terceira parte de "Distorted Beyond All Recognition", a necessidade de que a Teoria Crítica lance mão de um critério de justiça que possibilite o julgamento de reivindicações conflitantes, assim como o estabelecimento de quais delas são genuinamente emancipatórias, isto é, de quais promovem a justiça. De acordo com ela:

(...) a Teoria Crítica precisa de uma teoria de justiça não sectária. Longe de simplesmente assumir um esquema particular de valor ético, essa teoria precisa ser compatível com uma diversidade de visões razoáveis de boa vida. Ao mesmo tempo, entretanto, é igualmente implausível assumir que todas as reivindicações dignas, à primeira vista, de mérito, vão automaticamente convergir (...) A Teoria Crítica precisa incorporar uma teoria de justiça que de conta, simultaneamente, de duas condições. Por um lado, ela precisa ser suficientemente geral para evitar sectarismo. Por outro lado, ela precisa ser suficientemente determinada para adjudicar os conflitos. ${ }^{18}$

Temos, assim, que, para poder avaliar as diferentes reivindicações e apontar quais delas são ou não justas, os modelos de Teoria Crítica precisariam, segundo Fraser, possuir um critério normativo que conseguisse, mesmo tendo um conteúdo determinado, abarcar as diferentes concepções de boa vida, sendo, para tanto, suficientemente geral. Na tentativa de desenvolver essa teoria sem negligenciar nenhuma das suas duas exigências, Fraser retorna aos conceitos basilares da tradição liberal, igualdade de autonomia ${ }^{19}$ e valor moral dos seres humanos, e procura mostrar, num procedimento semelhante àquele apresentado por $\mathrm{Ra}-$ wls nas primeiras seções de seu Uma Teoria da Justiça, ${ }^{20}$ que deles decorre uma teoria de justiça que tem o princípio de paridade de participação como central. O objetivo de Fraser é partir de conceitos do liberalismo moderno para escapar de uma teoria que tenha como ponto de partida uma concepção de boa vida: o que ela busca é uma teoria que seja válida para todas elas, uma teoria moral e não ética, que, focada em questões de justiça e não de boa vida, seja universal. Isso porque, segundo ela: "normas de justiça são universalmente obrigatórias; como os princípios da Moralität kantiana, elas mantêm, independentemente dos atores, um comprometimento com valores específicos". ${ }^{21}$

I8 Fraser, N. "Distorted Beyond All Recognition”. In Redistribution or Recognition? p. 223-224.

I9 Para Fraser o conceito de igualdade de autonomia tem sua origem na tradição liberal, não na democrática. Cf. Fraser, N. "Distorted Beyond All Recognition”, p. 224.

20 Cf. Rawls, John. Uma Teoria da Justiça, São Paulo: Editora Martins Fontes, 2002.

2I Fraser, N. "Social Justice in the Age of Identity Politics". In Redistribution or Recognition? p. 28. 
Para afirmar a universalidade do princípio de paridade de participação, Fraser nega qualquer relação entre os ideais de igualdade de autonomia e valor moral dos seres humanos, e uma concepção de boa vida específica, ${ }^{22}$ segundo ela, esses ideais têm em vista possibilitar que os sujeitos da moralidade escolham, eles mesmos, qual concepção de ética adotar. Desta maneira, não apenas os conceitos fundamentais da tradição liberal não estariam comprometidos com uma concepção de boa vida, como seria, somente por meio deles, que as pessoas poderiam formular o que é, para elas, autorrealização. De acordo com Fraser, uma vez que estão livres, desde o princípio, de qualquer visão específica de boa vida, os conceitos de igualdade de autonomia e valor moral dos seres humanos, implicam, quando articulados deontologicamente, através de uma teoria compatível com diferentes visões éticas razoáveis, ${ }^{23}$ em uma teoria de justiça não sectária e com conteúdo normativo, cujo princípio central é o da paridade de participação. Esse princípio seria, então, o resultado de um desdobramento dos ideais do liberalismo moderno e, não só conseguiria dar conta de avaliar as múltiplas reivindicações, como também deixaria em aberto o espaço para a realização de uma pluralidade de concepções razoáveis de boa vida que respeitam a igualdade de autonomia e, portanto, o principio de paridade de participação.

Esse princípio é, assim, o critério de justiça que permite, da perspectiva da filosofia moral, avaliar se as normas às quais as reivindicações apelam são ou não moralmente válidas. Tendo, então, deduzido o princípio de paridade de participação a partir de dois ideais do liberalismo, Fraser passa a mostrar como, desse princípio, seguem-se também algumas consequências. É, dessa maneira, necessário explicitar o que Fraser entende por participação paritária e, o que, segundo ela, esse princípio de justiça requer para que seja preenchido. No que a isso se refere, ela afirma que:

rejeitando noções formais de igualdade como insuficientes, ele [o princípio] mantém que, para respeitar a igualdade de autonomia e valor moral dos outros, é preciso que se atribua a eles o status de parceiros integrais na interação social. $O$ que significa assegurar que todos tenham acesso aos pré-requisitos institucionais a uma participação paritária. ${ }^{24}$

22 Honneth nega que não haja relação entre o princípio de paridade de participação e uma concepção específica de boa vida. "Eu ainda não consigo ver como Fraser pretende introduzir a ideia de paridade de participação sem entendê-la como uma ideia particular de bem. (...) o princípio de igualdade só entrou em jogo como resultado do desenvolvimento histórico". Honneth, A. "Die Pointe der Anerkennung". In: Umverteilung oder Anerkennung?

23 Para Fraser, essa é a única maneira de articular as implicações da igualdade de autonomia. Cf. Fraser, N. "Distorted Beyond All Recognition". In Redistribution or Recognition?. p. 228.

24 Ibid., p. 229. 
De acordo com a autora, a realização de uma sociedade justa, isto é, de uma sociedade na qual o estatuto de parceiro paritário de interação é a todos atribuído, "exige a remoção de obstáculos econômicos a uma participação social integral", assim como "o desmantelamento de obstáculos culturais institucionalizados", 25 que impedem a paridade de participação. Uma sociedade justa exige, portanto, tanto redistribuição quanto reconhecimento.

Vemos, assim, que redistribuição e reconhecimento, antes caracterizados como duas gramáticas hegemônicas de contestação, são agora apresentados como exigências à realização de uma sociedade justa. Porém, se encontramos aqui uma convergência entre os paradigmas de justiça, aos quais os movimentos sociais recorrem em suas reivindicações e as duas formas de injustiça cuja necessidade de erradicação é deduzida ${ }^{26}$ através do princípio de paridade de participação, convergência essa que parece indicar a relação existente entre o momento descritivo e o momento normativo da teoria de Fraser, é importante ressaltar, contudo, que ela é resultado de uma contingência histórica. Redistribuição e reconhecimento, quando considerados do ponto de vista da teoria da justiça, são independentes dos mesmos conceitos, enquanto pensados da perspectiva dos paradigmas de justiça; mesmo que as reivindicações feitas pelos movimentos sociais ou quaisquer outras formas de organização política deixassem de existir, ou alterassem seu foco para exigências outras que não redistribuição de renda ou reconhecimento cultural, estes permaneceriam imprescindíveis para a realização de uma sociedade justa do ponto de vista da teoria da justiça.

Essa constatação mostra-se de extrema relevância se, retomando o que havíamos concluído anteriormente, lembrarmos que são os paradigmas populares de justiça, isto é, as gramáticas hegemônicas de contestação das quais os movimentos sociais lançam mão em suas reivindicações que constituem o ponto de referência empírico, por meio do qual Fraser procura relacionar o momento normativo de sua teoria com a facticidade, a saber, da transcendência com a imanência. Porém, se é assim, a relação dialética entre ambas, que a própria Fraser estabeleceu como pressuposto da validade da crítica, se apresenta como extremamente frágil. Uma simples mudança nas diretrizes dos movimentos sociais que resulte na alteração dos paradigmas de justiça (mudança essa que poderíamos até mesmo encontrar no diagnóstico de época apresentado por Fraser,

25 Fraser, N. "Distorted Beyond All Recognition", p. 229. Cf. também: Fraser, N. "Social Justice in the Age of Identity Politics”. In Redistribution or Recognition?, p. 36.

26 Essa dedução leva em conta as configurações sociais atuais. O resultado da aplicação do princípio de paridade de participação na sociedade contemporânea, aponta para o fato de que, para que esta venha a se tornar justa, é preciso tanto redistribuição de renda quanto reconhecimento cultural. Cf. Idem, pp. 30-37. 
Algumas considerações sobre o estatuto da crítica em Nancy Fraser

segundo o qual as reivindicações por redistribuição material estariam se tornando cada vez mais escassas) faria que o ponto de referência empírico deixasse de existir, o que, por sua vez, teria como consequência a dissolução da dialética entre imanência e transcendência, sem a qual a crítica se torna puramente transcendente.

As pedras de toque que permitiriam a relação entre a crítica e seu contexto social, a saber, os paradigmas de justiça, não possuem uma relação intrínseca com a teoria da justiça. ${ }^{27}$ Uma mudança nos paradigmas de justiça não altera as exigências deduzidas a partir da teoria da justiça, assim como as mudanças na teoria da justiça não alteram as gramáticas hegemônicas de contestação; esses dois momentos são independentes entre si. Assim, a dimensão normativa da teoria proposta por Fraser parece estar descolada das relações sociais; não é dos pontos de referência - os responsáveis pela relação entre imanência e transcendência - que, segundo ela, os elementos críticos de sua teoria são extraídos, segundo ela, - A crítica é feita por meio de uma teoria da justiça que, deontológica, não possui nenhuma relação forte com o presente. Estando essa interpretação correta, o

27 Temos, contudo, que a relação que se estabelece, em Fraser, entre a teoria da justiça e seus pontos de referência empírico é bastante complexa. É possível encontrar passagens que fazem afirmações distintas sobre o fundamento do princípio de paridade de participação, assim como sobre qual o papel dos teóricos críticos. Em alguns momentos, por exemplo, Fraser parece afirmar que esse princípio é resultado dos paradigmas de justiça, uma vez que seria somente uma teoria da justiça guiada por ele, que daria conta da totalidade das reivindicações existentes. Ao fazer isso, a autora parece procurar fortalecer a relação entre imanência e transcendência proposta por ela, o que, a nosso ver, não acontece. Isso porque, se interpretarmos o princípio de paridade de participação somente como o resultado de uma junção entre os paradigmas de justiça apresentados, o modelo teórico de Fraser acabaria por sucumbir, mais uma vez, à crítica de Benhabib. A própria teoria de justiça que seria responsável pela avaliação dos conflitos sociais e pelo estabelecimento de quais dentre eles são legítimos, assim como pela exclusão daqueles que não o são, (sem a qual não seria possível restringi-los a apenas aqueles que lançam mão desses paradigmas normativos) seria, ao mesmo tempo, vista como o resultado da união dos paradigmas que já o pressupõem. O que, senão constitui uma tautologia, na qual o princípio de paridade de participação já estaria implícito no diagnóstico de época proposto pela autora, indica a presença de outro critério normativo que, não explicitado, teria permitido a ela, o estabelecimento desses paradigmas. Ou, no caso de vermos o princípio de paridade de participação como o resultado de uma teoria da justiça que una os paradigmas de justiça existentes na sociedade e, simultaneamente, como o desdobramento de uma interpretação democrática de dois princípios do liberalismo, a relação entre essas duas perspectivas seria, ainda assim, contingente. Cf. Fraser, N. "Social Justice in the Age of Identity Politics", p. 34-37. Cf. também. "Distorted beyond Recognition”, p. 2IO. Na maior parte do texto, entretanto, o critério é derivado de uma teoria da justiça, que não resulta desses mesmos paradigmas. Gf. Idem, p. 208. 
modelo teórico proposto por Fraser não conseguiria dar conta de seus próprios objetivos; sem preencher seus pressupostos teóricos, a saber, sem conseguir extrair seu momento crítico de uma compreensão sistemática da sociedade contemporânea, a teoria proposta por Fraser não faria crítica imanente. Entra, assim, em questão se o pensamento de Fraser é realmente crítico. Questão essa que, longe de se propor a responder, o presente artigo procura apenas apresentar.

\section{Referências bibliografias.}

Benhabib, Seyla. , Situating the Self - Gender, Community and Postmodernism in Contemporary Ethics, New York: Routledge, I992.

"Sobre um modelo deliberativo de racionalidade democrática". In: Democracia Deliberativa. Werle, Denílson Luiz e Melo, Rúrion Soares (orgs.), São Paulo, Esfera Pública, 2007.

Honneth, Axel. "Umverteilung als Anerkennug. Eine Erwiderung auf Nancy Fraser". In: Umverteilung oder Anerkennung? Eine politisch-philosophische Kontroverse. Frankfurt am Main: Suhrkamp Verlag, 2003, pp. I29-225.

"Die Pointe der Anerkennung. Eine Entgegnung auf die Entgegnung”. In: Umverteilung oder Anerkennung? Eine politisch-philosophische Kontroverse. Frankfurt am Main: Suhrkamp Verlag, 2003, pp. 27I-305.

Fraser, Nancy. "What's Critical About Critical Theory? The case of Habermas and the Gender". New German Critique, n.35, pp. 97-I3I. ["Que é Crítico na Teoria Crítica? O Argumento de Habermas e o Gênero". In: Feminismo como Crítica da Modernidade, Benhabib, S. e Cornell, D. (orgs.), Rio de Janeiro: Rosa dos Tempos, I987, p. 38.]

"Social Criticism without Philosophy: An Enconter between Feminism and Postmodernism", in Theory Culture and Society, I988, v. 5. - Unruly Practices. Power, Discourse and Gender in Contemporary Social Theory. Minneapolis: University of Minnesota Press. I989.

Justice Interruptus. Critical reflections on the 'postsocialist' condition.

New York \& London: Routledge, I997. 
Algumas considerações sobre o estatuto da crítica em Nancy Fraser

"Social Justice in the Age of Identity Politics: Redistribution, Recognition, and Participation". In: Redistribution or Recognition? A Political-Philosophical Exchange. New York \& London: Verso. 2003.

"Distorted Beyond All Recognition: A Rejoinder to Axel Honneth". In Redistribution or Recognition? A Political-Philosophical Exchange. New York \& London: Verso. 2003.

pp. 69-9o.

. "Reframing Global Justice”. New Left Review, n. 36, 2005,

"Mapping Feminist Imagination: From Redistribution to Recognition Representation". Constellations, v. I2, n. ${ }^{\circ}$ 3, 2005, pp. 295-307.

Rawls, J. Uma Teoria da Justiça, São Paulo: Editora Martins Fontes, 2002.

Silva, Felipe G. "Iris Young, Nancy Fraser e Seyla Benhabib: uma disputa entre modelos críticos". In: Teoria Crítica. No prelo.

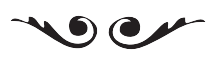

Nathalie Bressiani de Almeida é graduada em Filosofia pela USP.

E-mail: nathbressiani@hotmail.com 